\title{
Socio-economic Impacts of COVID-19 in Woldia City, North Wollo Zone, Amhara Region, Ethiopia
}

\author{
Alemayehu Amsalu Alen*, Gashu Workneh Kassie, Tawechew Guadea Meberatu \\ Department of Statistics, University of Gondar, Gondar, Ethiopia \\ Email address: \\ alex8100amsalu@gmail.com (A. A. Alen), gashuwor@gmail.com (G. W. Kassie), tawachew93@gmail.com (T. G. Meberatu) \\ ${ }^{*}$ Corresponding author
}

\section{To cite this article:}

Alemayehu Amsalu Alen, Gashu Workneh Kassie, Tawechew Guadea Meberatu. Socio-economic Impacts of COVID-19 in Woldia City, North Wollo Zone, Amhara Region, Ethiopia. International Journal of Economic Behavior and Organization. Vol. 9, No. 3, 2021 , pp. $42-48$. doi: $10.11648 /$ j.ijebo.20210903.11

Received: July 23, 2021; Accepted: August 6, 2021; Published: August 11, 2021

\begin{abstract}
The global novel corona virus diseases COVID-19 pandemic was socio-economic crisis in all aspects of the human life. The impact of COVID-19 reflects our best collective available evidence, knowledge and expertise of the scale, nature and depth of socio-economic impacts in the country. We offer this as contribution to the expanding knowledge base on this critical issue, acknowledging and drawing upon the work of the government of Ethiopia, academic experts, development partners and consultants on this issue. Analysis of socio-economic impacts of COVID-19 and to identify factors affecting socio-economic impacts of COVID-19 in Woldia city from the human beings. A Cross-sectional data was carried out between November and December 2020 in Woldia city from Ethiopia. A total of 383 samples using simple random sampling were interviewed. The binary logistic regression was applied to identify the effect of predictor variables on socio-economic impacts of COVID-19. According to the results in the study, $79.11 \%$ have and $20.89 \%$ have not socio-economic impacts of COVID-19 respondents have been involved respectively. The ages more than 15 was influenced in this study. From results age, challenges, family size, psychological impact and marital status were significantly affects COVID-19. The overall socio-economic impacts of COVID-19 in this study were critical issue. The study strongly suggests that more could be done to assure socio-economic impacts of COVID- 19 provided were more carefulness.
\end{abstract}

Keywords: Corona Virus, COVID-19, Binary Logistic Regression, Woldia City, Ethiopia

\section{Introduction}

The global Novel corona virus diseases COVID-19 pandemic is unprecedented crisis unlike any since the end of the Second World War (WWII) [1]. It is the most powerful sign to date of what happens when uncontrolled expansion of human activity collides with the realities and boundaries of the planet [2]. There is much to be learnt from corona virus diseases 2019 (COVID-19) pandemic and to be done in response now and into the future, individual, community, societal and global scale [3]. Older persons above the age of 60 are more likely to have serious COVID-19 illness once infected, as older persons have generally lower immune systems compared to other age groups. The is age specific COVID-19 death rates which are skewed towards older persons about $95 \%$ of people who have reportedly died of COVID-19 in Europe were over 60 years of age [4]. From this study, the age groups between 15-64 and above 64 were high crisis of socio economic impact of COVID-19.

Today the immediate implications of the crisis in SubSaharan Africa (SSA) are already serious. Despite the still relatively small caseload, which gives a misleading impression of the scale and depth of the crisis, the sharp deterioration of global conditions and the response measures taken in the region to combat the pandemic have already precipitated a major socio-economic crisis [5].

Ethiopia faced the onset of the crisis with clear strengths. It had excellent long term track record of economic growth, major improvements in infrastructure, poverty reduction and social development [6]. The country also had ambitious vision of economic transformation captured in the homegrown economic reform programmed that builds on the foundation of past successes, but also recognizes the macroeconomic, structural and sectoral shortfalls that have emerged as a 
consequence, requiring a different economic approach in the future [7]. Ethiopia was also on the ways of most important political transition in a generation, with a major opening up of political and civic space and plans underway for the country's first democratic elections [8]. In several aspects, Ethiopia was better positioned developmentally to withstand and overcome the crisis than many others in SSA Ethiopia, however, faced some major vulnerability as it was struck by COVID-19 [9]. The macroeconomic and development situation was challenging, evident in slowing, but still high growth, the risk of debt distress, low levels of domestic resource mobilization, high inflation, high unemployment, not least among youth trying to find opportunities in an economy with elevated levels of informality, low forex reserves and significant pressure on the exchange rate of the Birr [9].

The importance of reduction socio economic impact of COVID-19 was giving the consultancy in each aspects of daily human activities [18]. The Woldia city was selected for the present study. This study was designed to assess socio economic impact of COVID-19 and to know the relationship between socio economic factors of COVID-19 and explanatory variables and to identify significant effects on socio economic impact of COVID-19. We want to insure socio economic impact of COVID-19 in Woldia city by using logistic regression model.

\section{Methods}

\subsection{Study Area}

This study was conducted in Woldia city in the North Wollo Zone away from $521 \mathrm{kms}$ from Addis Ababa and 370 kms from Bahir dar city in Amhara region, Ethiopia.

\subsection{Study Design}

A cross sectional study design was conducted between November and December 2020.

\subsection{Sampling Method}

Simple random sampling was used where the researcher draws simple random samples was using equal probability selection of the samples from the target population in this study. The lottery methods of selection was applied for this data collection by self-administered questionnaire.

\subsection{Sample Size}

The sample size for this study was determined based on simple random sampling at $95 \%$ confidence level. Based on the 2019 national census conducted by central statistical agency of Ethiopia (CSA), the population size of the Woldia city were 180,000 of whom 81,750 were men and 98,250 women [10]. The sample size formula is given by [11]

$$
\mathrm{n}=\frac{\text { no }}{1+\frac{\mathrm{no}}{\mathrm{N}}}, \text { where } \mathrm{n}_{0}=\frac{\mathrm{Z}_{\frac{\alpha}{2}}{ }^{2} \mathrm{pq}}{\mathrm{d}^{2}}
$$

Assume the margin of the error 5\% and to identify the probability of success (p) and failure (q), the pilot survey was conducted in this study. From the total of 180 thousands of populations in Woldia city, 80 of them were yes there was COVID-19 impact and 70 were not impact using simple random sampling and questionnaire of 150 individuals.

$$
\begin{aligned}
& \mathrm{P}=\frac{\text { Success }}{\text { Total }} \text { and } \mathrm{q}=\frac{\text { Failures }}{\text { Total }} \text {. Hence, } \mathrm{P}=\frac{80}{150}=0.533 \text { and } \mathrm{q}= \\
& \frac{70}{150}=0.467 \\
& \mathrm{n}_{0}=\frac{1.96 * 196 * 0.533 * 0.467}{0.05 * 0.05}=382.49 \cong 383 \text {. And, } \frac{\mathrm{n}_{0}}{\mathrm{~N}}=\frac{383}{180,000} \\
& =0.0021<5 \% \text {. }
\end{aligned}
$$

So that, the initial sample size, $\mathrm{n}_{0}=\mathrm{n}$. Therefore, the required sample size in this study was 383 .

\subsection{Data Collection Instrument}

The data collection instrument was closed ended questionnaire. The first draft of questionnaire was prepared by authors and re-organized by co-authors. The data collection was 10 female and 15 male of community fluent speakers in Amharic, who were not working in the study of total 25 collectors participated. Two days theoretical training was given before data collection.

\subsection{Study Variables}

The response variable in this study was the socioeconomic impact of COVID-19. The response variable was a dichotomous category, and thus code as the values 1 for yes there is socio-economic impact and 0 for no socio-economic impact. The predictor variables were Age, Sex, Marital status, Family size, Occupation, Religion, Educational level, Challenges, Unemployment rate, Sectors, Housing status, Psychology and Economic sectors.

\subsection{Data Entry and Analysis}

The completed questionnaires were checked for completeness and consistency by the authors and co-authors. Data was entered, cleaned and analyzed using SPSS 24 and STATA 16. After all the data gathered, then analyze using descriptive statistics in qualitative and quantitative data. Qualitative analysis of the descriptive statistics method like table, percent, bar chart, and frequency distribution were used. In this study the inferential statistics was going to used logistic regression model. The dependent variable was socio economic impact of COVID19 and it was qualitative form which two possibilities, who have yes and no socio economic impact of COVID 19.

\subsection{Chi-square Test}

The variable $\chi^{2}$ distribution, in this statistical procedure there is relationship between two categorical variables or not.

\subsection{Logistic Regression}

Logistic regression analysis extends the techniques of regression analysis to research situations in which the outcome variable was categorical. The response variable is binary, such as (yes or no, presence or absence, success or failure etc.) in logistic regression [12].

Assumptions should consider the efficient use of logistic 
regression given as follow [13]. The binary logistic regression was code the dependent class of interest as 1 and other class as 0 . It does not assume a linear relationship between the response and explanatory variables. The response variable must be categorical. The predictor variables not (normally distributed, linearly related, multicollinarity and equal variance) within each group. The logit regression should linear relationship with the logit form of the response variable.

The parameters estimation was maximum likelihood and non-iterative weighted least squares are the two most computing estimation methods used in fitting logistic regression model [14].

The goodness of fit involves investigating how close values predicted by the model with that of observed values [15]. The comparison of observed to predicted values using the likelihood function is based on the statistic was deviance.

The likelihood ratio test statistic is the test statistic commonly used for assessing the overall fit of the logistic regression model. The likelihood-ratio test uses the ratio of the maximized value of the likelihood function for the full model over the maximized value of the likelihood function for the simpler model [15].
The Wald statistic was commonly used to test the significance of individual logistic regression coefficients for each independent variables. The Wald test weren't significant, then explanatory variables could be omitted from the model [17].

The final measure of model fit is the Hosmer and Lemeshow goodness of fit statistic, which measures the correspondence between the actual and predicted values of the dependent variable [16].

\section{Results and Discussion}

The study was conducted 2013 E.C or 2020/2021 G.C in Woldia city North Wollo Zone in Amhara region Ethiopia. The data collection period was between November and December 2020. As result, a total of 383 samples from this city were participated in the survey with 303 (79.11\%) of them have the existence of the socio economic impact and 80 (20.89\%) obtained haven't the socio-economic impact of the COVID-19. The descriptive statistics was discussed in (Tables 1-2 and Figures 1-7).

Table 1. Impacts of COVID-19 vs predictors, Woldia City, Ethiopia.

\begin{tabular}{|c|c|c|c|c|c|}
\hline \multirow{3}{*}{ Explanatory variables \& category } & & \multicolumn{4}{|c|}{ Socio Economic Impact of COVID-19 } \\
\hline & & \multicolumn{2}{|l|}{ Yes } & \multicolumn{2}{|l|}{ No } \\
\hline & & Frequency & Percent & Frequency & Percent \\
\hline \multirow{3}{*}{ Sex } & Male & 140 & 36.55 & 0 & 0.00 \\
\hline & Female & 163 & 42.56 & 80 & 20.89 \\
\hline & Below 15 & 113 & 29.50 & 14 & 3.66 \\
\hline \multirow[t]{2}{*}{ Age } & Between 15-64 & 100 & 26.11 & 55 & 14.36 \\
\hline & Above 64 & 90 & 23.50 & 11 & 2.87 \\
\hline \multirow{2}{*}{ Increase unemployment rate } & Yes & 239 & 62.40 & 54 & 14.10 \\
\hline & No & 64 & 16.71 & 26 & 6.79 \\
\hline \multirow{3}{*}{ Family size } & Null & 14 & 3.66 & 4 & 1.04 \\
\hline & Between 1-5 & 166 & 43.34 & 68 & 17.75 \\
\hline & More than 5 & 123 & 32.11 & 8 & 2.09 \\
\hline \multirow{3}{*}{ Challenges } & Political & 43 & 11.23 & 27 & 7.05 \\
\hline & Social & 208 & 54.31 & 42 & 10.97 \\
\hline & Economic & 52 & 13.58 & 11 & 2.87 \\
\hline \multirow{3}{*}{ Housing Status } & Rented & 100 & 26.11 & 0 & 0.00 \\
\hline & Owned & 90 & 23.50 & 55 & 14.36 \\
\hline & Within family & 113 & 29.50 & 25 & 6.53 \\
\hline
\end{tabular}

Considering the samples of women were $163(42.56 \%)$ and $140(36.55 \%)$ have socio-economic impact of COVID-19 and $80(20.89 \%)$ and $0(0.00 \%)$ haven't socio-economic impact of COVID-19 respectively. So that, most of the women were failed socio-economic impact of the novel corona virus diseases COVID-19. With regard to age results, the corona virus COVID-19 its own impact without selection of the age. Since, the age of all categories have socio economic impact of COVID-19. According to increase unemployment rate results were $239(62.40 \%)$ and 54 $(14.10 \%)$ have no socio-economic impact of the novel corona virus COVID-19 respectively. As result of housing status 100 $(26.11 \%), 90(23.50 \%)$ and $113(29.50 \%)$ have socio economic impact of COVID-19 and $0(0.00 \%), 55$ (14.36\%) and $25(6.53 \%)$ have not socio economic impact of COVID-
19 rented, owned and within family respectively. Therefore, all rented were socio economic impact of COVID-19 than owned and within family. With the case of family size between 1-5 and more than 5 family have highest socio economic impact of the novel corona virus COVID-19 than with no family. In case of the challenges, social have higher than political and economic socio economic impact of the novel corona virus diseases COVID-19. According to the results, most of the peoples have the socio-economic impact of the novel corona virus diseases COVID-19.

Table 2. Socio-Economic Impacts of COVID-19, Woldia City, Ethiopia.

\begin{tabular}{lll}
\hline Socio-Economic impact of COVID-19 & Frequency & Percent \\
\hline Yes & 303 & 79.11 \\
No & 80 & 20.89 \\
\hline
\end{tabular}


Out of 383 samples considered in the analysis, $79.11 \%$ have socio-economic impact and $20.89 \%$ have no socioeconomic impact of COVID-19 during the time of data collection. That means most of the society in Woldia city have socio-economic impact of COVID-19. So that, the peoples living in this city was socially and economically in crisis due to the case of COVID-19.

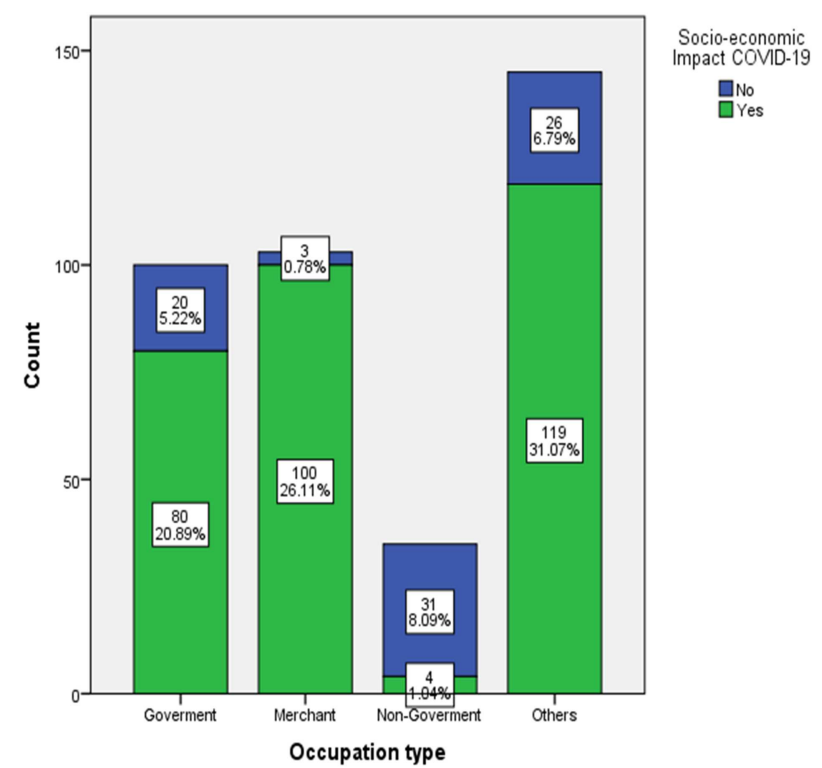

Figure 1. Occupation Types of COVID-19, Woldia City, Ethiopia.

Occupation types, out of 383 samples who have socio economic impact of COVID-19 20.89\%, 26.11\%, 1.04\% and $31.07 \%$ were government, merchant, non-government and others respectively. Since, merchants and others have highest socio economic impact of COVID-19.

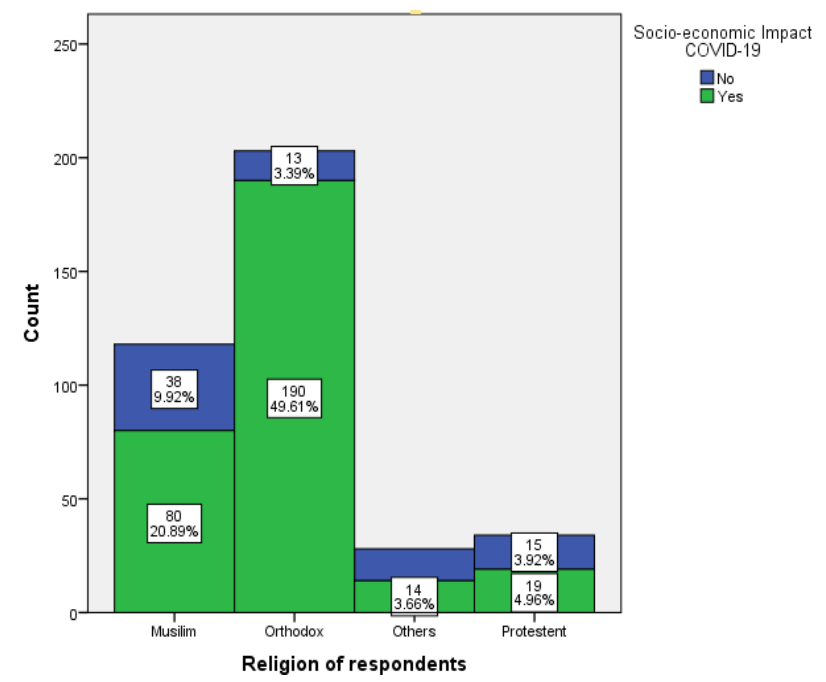

Figure 2. Religions of COVID-19, Woldia City, Ethiopia.

Religions orthodox and Muslim were highest socio economic impact of the novel corona virus COVID-19. So that, from Ethiopia most of the populations were followers of orthodox and Muslim have more socio economic impact of COVID-19.

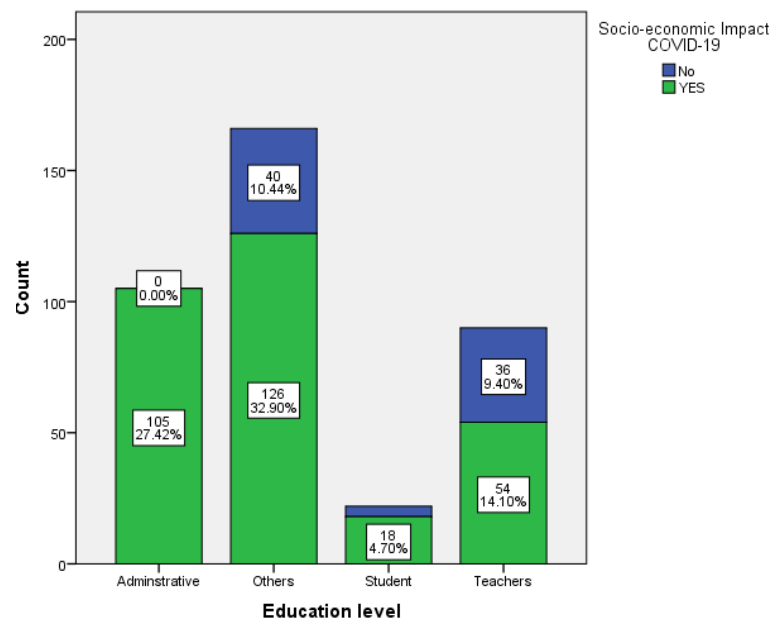

Figure 3. Educational level of COVID-19, Woldia City, Ethiopia.

Educational level who have administrative, others, teachers and students socio-economic impact of COVID-19 $27.42 \%, 32.90 \%, 14.10 \%$ and $4.70 \%$ respectively. Due to this result, others and administrative have highest socio economic impact of COVID-19.

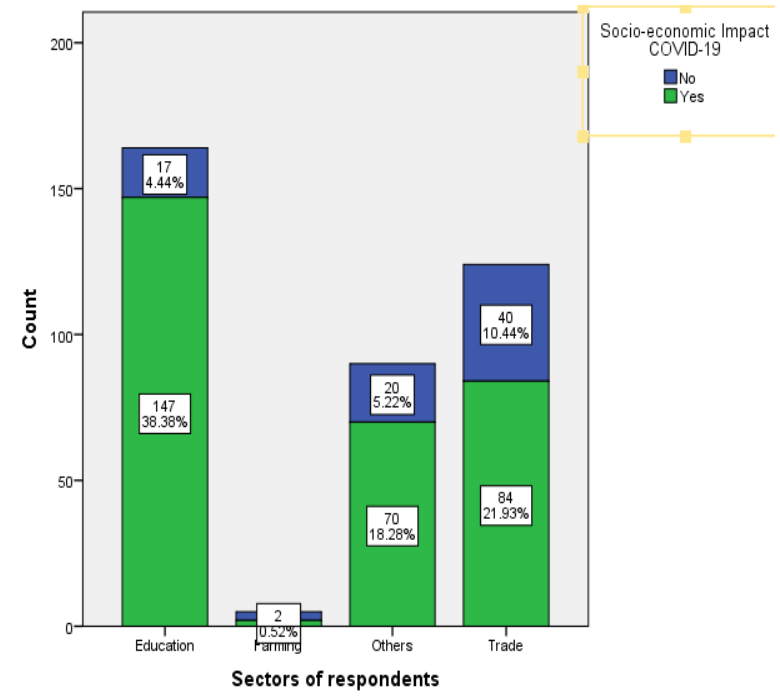

Figure 4. Sectors impact of COVID-19, Woldia City, Ethiopia.

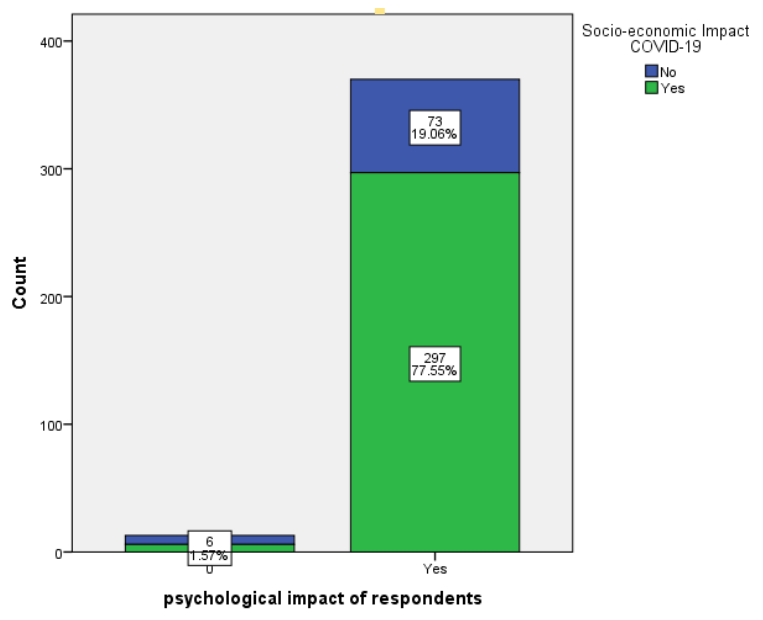

Figure 5. Psychological impact of COVID-19, Woldia City, Ethiopia. 
Sectors, who have socio economic impact of COVID-19 $38.38 \%, \quad 0.52 \%, \quad 18.28 \%$ and $21.93 \%$ were education, farming, others and trade respectively. Since, education and trade have highest socio economic impact of COVID-19. And trade have similarly high benefits or profit obtained from the virus COVID-19.

Psychological impact, who have socio economic impact of COVID-19 297 (77.55\%) and 7 (1.83\%) and 73 (19.06\%) and 6 (1.57\%) were having greatest Psychological impact of COVID19 and non-Psychological impact of COVID-19 respectively.

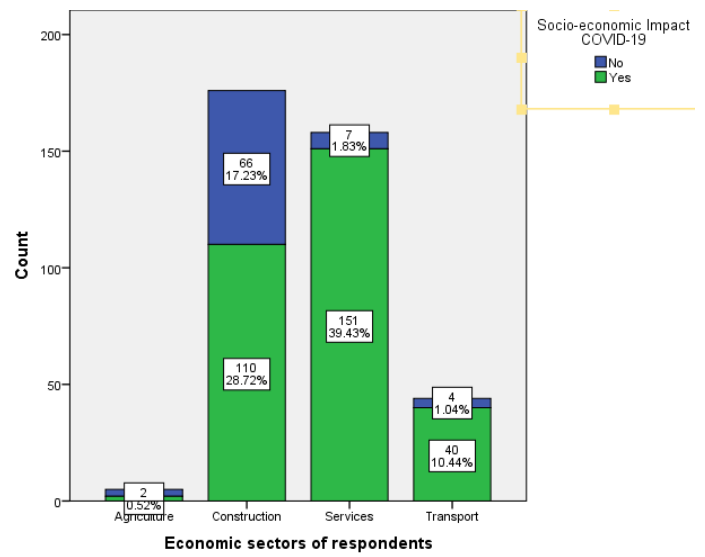

Figure 6. Economic sectors of COVID-19, Woldia City, Ethiopia.

Economic sectors, whose values $151(39.43 \%)$ in services was highest as compared to other economic sectors and agriculture $2(0.52 \%)$ have lowest socio economic impact of COVID-19. But, COVID-19, in all sectors there was socio economic impact of COVID-19.

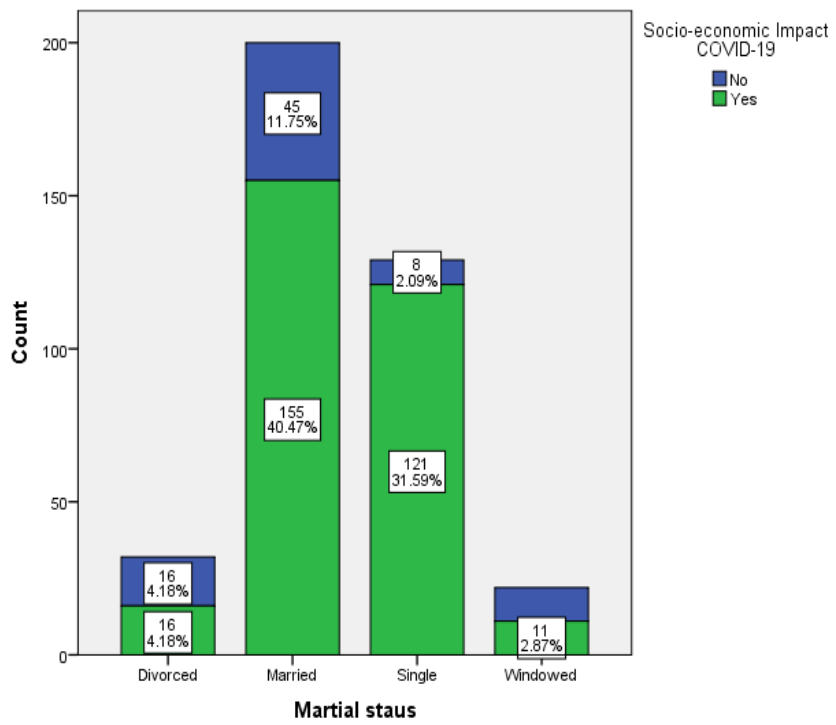

Figure 7. Marital Status of COVID-19, Woldia City, Ethiopia.

Marital status, who have socio-economic impact of COVID-19 married 155 (40.47\%) and windowed 11 (2.57\%) were highest and lowest socio-economic impact of COVID19 respectively. Since, marriage was highest socio-economic impact of COVID-19.

\subsection{Inferential Statistics}

In this study, the parameters were discussed by using significance level (p-value or sig.). The inferential statistics was discussed in (Tables 3-5).

Table 3. Impacts vs. Predictors of COVID-19, Woldia City, Ethiopia.

\begin{tabular}{|c|c|c|c|}
\hline Impact COVID-19 vs. Predictor Variables & Pearson $\chi^{2}$ & Likelihood ratio & Sig. \\
\hline Age & 33.57 & 33.25 & 0.00 \\
\hline Sex & 58.26 & 84.61 & 0.00 \\
\hline Family size & 26.80 & 31.19 & 0.00 \\
\hline Occupation Type & 117.98 & 104.06 & 0.00 \\
\hline Religion of respondents & 60.38 & 62.18 & 0.00 \\
\hline Education Level & 48.75 & 67.22 & 0.00 \\
\hline Challenges of respondents & 16.22 & 14.50 & 0.00 \\
\hline Unemployment rates & 4.56 & 4.32 & 0.047 \\
\hline Sectors of respondents & 25.41 & 25.29 & 0.00 \\
\hline Psychology & 8.85 & 7.10 & 0.01 \\
\hline Economic sectors & 63.623 & 68.82 & 0.00 \\
\hline Marital status & 44.85 & 44.44 & 0.00 \\
\hline
\end{tabular}

All variables output have likelihood ratio test and Pearson chi square with rejection of null hypothesis significantly affects socio-economic impact of COVID-19. Since, P-values less than 5\% shows that there is association between socio-economic impact of COVID-19 and predictor variables.

Table 4. Variables in the equation COVID-19, Woldia City, Ethiopia.

\begin{tabular}{|c|c|c|c|c|c|c|c|}
\hline \multirow{2}{*}{ Explanatory variables } & \multirow{2}{*}{$\boldsymbol{\beta}$} & \multirow{2}{*}{ S.E } & \multirow{2}{*}{ Wald } & \multirow{2}{*}{ Sig } & \multirow{2}{*}{$\operatorname{Exp} \beta$} & \multicolumn{2}{|c|}{$95 \%$ CI for $\operatorname{Exp}(\beta)$} \\
\hline & & & & & & Lower & Upper \\
\hline Age (15-64) & 105.67 & 49678.06 & 0.00 & 0.00 & $7.77 \mathrm{E}+045$ & 0.00 & $9.53 \mathrm{E}+048$ \\
\hline Age $(64+)$ & 106.08 & 46845.95 & 0.00 & 0.00 & $1.18 \mathrm{E}+046$ & 0.00 & $2.35 \mathrm{E}+049$ \\
\hline Family size (1-5) & 0.370 & 24615.05 & 0.00 & 0.00 & 1.45 & 0.00 & 5.00 \\
\hline Family size $(5+)$ & 2.39 & 27668.01 & 0.00 & 0.00 & 10.89 & 0.00 & 25.00 \\
\hline Challenges (social) & 2.47 & 45787.96 & 0.00 & 0.00 & 11.80 & 0.00 & 15.11 \\
\hline Challenges (economic) & -1.63 & 8895.13 & 0.00 & 0.00 & 0.20 & 0.00 & 4.32 \\
\hline Psychological impact (yes) & -0.53 & 17515.68 & 0.00 & 0.00 & 0.59 & 0.00 & 1.52 \\
\hline
\end{tabular}




\begin{tabular}{|c|c|c|c|c|c|c|c|}
\hline \multirow{2}{*}{ Explanatory variables } & \multirow{2}{*}{$\boldsymbol{\beta}$} & \multirow{2}{*}{ S.E } & \multirow{2}{*}{ Wald } & \multirow{2}{*}{ Sig } & \multirow{2}{*}{$\operatorname{Exp} \beta$} & \multicolumn{2}{|c|}{$95 \%$ CI for $\operatorname{Exp}(\beta)$} \\
\hline & & & & & & Lower & Upper \\
\hline Marital Status (married) & 0.24 & 12118.35 & 0.00 & 0.00 & 1.27 & 0.00 & 2.30 \\
\hline Marital Status (divorced) & -0.83 & 10131.67 & 0.00 & 0.00 & 0.44 & 0.00 & 1.32 \\
\hline Marital Status (windowed) & 6.84 & 42881.80 & 0.00 & 0.00 & 929.59 & 0.00 & 1211.12 \\
\hline Constant & -130.37 & 45296.94 & 0.00 & 0.00 & 0.00 & & \\
\hline
\end{tabular}

The odds whose age from 15-64 and above 64 were $7.77 \mathrm{E}+045$ and $1.18 \mathrm{E}+046$ respectively times more likely to socio economic impact of COVID-19 as compared to those age below 15 . The odds whose family size $1-5$ and above 5 were 1.45 and 10.89 respectively times more likely to socio economic impact of COVID-19 as compared to those no family. The odds whose social challenges and economic challenges were 11.80 time more likely and 0.20 times less likely to socio economic impact of COVID-19 respectively as compared to those political challenges. The odds whose Psychological impact was 0.59 times less likely to socio economic impact of COVID-19 as compared to those no Psychological impact of COVID-19. The odds whose marital status married and windowed were 1.27 and 929.59 time more likely and divorced 0.44 times less likely to socio economic impact of COVID-19 respectively as compared to those single marital status. From result $\operatorname{Exp}(\beta)$ were lies between the confidence interval and all values of Wald statistics and p-values less than $5 \%$ implies that significantly affecting the socio economic impact of the novel corona virus COVID-19.

\subsection{Logistic Regression Model Fit}

The fitted model for logistic regressions: Logit $\pi(\mathrm{x})=$ $130.37+105.67$ age $(15-64)+106.08$ age $(64+)+0.37$ family $(1-5)+2.39$ family $(5+)+2.47$ (social) -1.63 (economic) 0.53 psychological impact +0.24 (married) -0.83 (divorced) +6.84 (windowed).

According to the above logistic regression model the coefficient can be interpreted as change in the logit changes a one unit in the independent variables. For instance, one unit change the coefficients of the variables age (15-64) and 64+ logit units of the socio economic impact of the novel corona virus COVID-19 change by 105.67 and 106.08 units respectively.

Table 5. Hosmer and Lemshow test of COVID-19, Woldia City, Ethiopia.

\begin{tabular}{llll}
\hline Step & Chi-square & Df & Sig. \\
\hline 1 & 0.00 & 7 & 1.000 \\
\hline
\end{tabular}

The non-significance of the chi-square value reject the null hypothesis is no difference between the observed and expected frequencies. The insignificant $p$-value shows that, the model adequacy fits the data very well (Table 5).

\subsection{Discussions}

This paper presents a study that estimated the level of socio-economic impact of COVID-19 in Woldia city, North Wollo Zone, Amhara Region of Ethiopia. The study was provided that factors that determined the socio-economic impact of COVID-19. According to the results, about 20.89\% and $79.11 \%$ of the respondents' haven't and have socioeconomic impact of COVID-19 respectively. This indicates that most of the Woldia city populations have socioeconomic impact of COVID-19. As compared to the age groups above 60 years was died the most impacted and in this study above 15 and older ages have impact of socioeconomic of the COVID-19. The marital status married affected socio-economic impact of COVID-19 than any other status of marriage. Peoples having high family size infected socio-economic impact of COVID-19 more than low family. Since, low family size was lower socio-economic impact of COVID-19.

Our findings showed that more than two-thirds of all samples considered in the study were very likely to recommend the socio-economic impacts of COVID-19 interference should be reduced. Though this suggests that carefulness, strong psychology, low family size, without marriage (single) and limiting the challenged areas have better reduction of the socio-economic impacts of the novel corona virus diseases COVID-19.

\section{Conclusions}

The study strongly suggests that more could be done and more should be reduction of socio-economic impact of COVID-19 interference. The main objective of this study was to study factors affecting the socio-economic impact of COVID-19. The socio-economic impact of COVID-19 shows that samples 383 considered, $79.11 \%$ were found to have socio-economic impact of COVID-19 and 20.89\% of them were not found socio-economic impact of COVID-19 at the time of the study period. The binary logistic regression showed that age, family size, challenges, psychological impact and marital status were the major factors that affect the socio-economic impact of COVID-19. This study also indicated that sex, housing status, religion, economic sectors, unemployment rates, education level and sectors of respondents were not significant predictors of the socioeconomic impact of COVID-19. General recommendations given for all concerned bodies, all populations should have not disturbed and give attention the socio-economic impact of COVID-19.

\section{Authors' Contributions}

The proposal was written, participated in data collection, analyzed the data and paper draft was done. Also, approved the proposal with some revisions, participated in data analysis and revised subsequent drafts of the paper coauthors. The authors read and approved the final manuscript. 


\section{Acknowledgements}

The authors would say thanks Woldia city communities for monitoring the data collection process. The author also thanks in University of Gondar Kasim Mohamad (associate prof.) for comments and editing the manuscript. Finally, great thanks my wife Alemtsehaye Asires Engidew her support all activities of Luel and Barcon Alemayehu Amsalu during the time of data collection up to analyzed.

\section{References}

[1] Tovar, J., Soccer, World War II and coronavirus: a comparative analysis of how the sport shut down. Soccer \& Society, 2020: p. 1-9.

[2] Alimi, T., et al., COVID-19 and Religious Ethics, 2020, Wiley Online Library.

[3] Mirbabaie, M., et al., Social media in times of crisis: Learning from Hurricane Harvey for the coronavirus disease 2019 pandemic response. Journal of Information Technology, 2020. 35 (3): p. 195-213.

[4] Davies, N. G., et al., Age-dependent effects in the transmission and control of COVID-19 epidemics. Nature medicine, 2020. 26 (8): p. 1205-1211.

[5] Nchanji, E. B., et al., Immediate impacts of COVID-19 pandemic on bean value chain in selected countries in subSaharan Africa. Agricultural Systems, 2021. 188: p. 103034.

[6] Carvalho, S., et al., Planning for School Reopening and Recovery After COVID-19. Center for Global Development, 2020.

[7] Fick, D. S., Entrepreneurship in Africa: A study of successes. 2002: Greenwood Publishing Group.

[8] Temin, J. and Y. Badwaza, Aspirations and Realities in Africa: Ethiopia's Quiet Revolution. Journal of democracy, 2019. 30 (3): p. 139-153.
[9] Tesso, G., The Economics of COVID-19: Economic Growth, Unemployment and the Challenge to Progress out of Poverty in Ethiopia.

[10] Asmare, L. D., et al., Prevalence and Factors Associated with Child Feeding Practice Among Mothers of Woldia Town, Northeast Ethiopia. Nutrition and Dietary Supplements, 2020. 12: p. 205-213.

[11] Cochran, W. G., Sampling techniques. 2007: John Wiley \& Sons.

[12] Dayton, C. M., Logistic regression analysis. Stat, 1992: p. 474-574.

[13] Stefanski, L. A., R. J. Carroll, and D. Ruppert, Optimally hounded score functions for generalized linear models with applications to logistic regression. Biometrika, 1986. 73 (2): p. 413-424.

[14] Sarkar, S., H. Midi, and S. Rana, Model selection in logistic regression and performance of its predictive ability. Australian Journal of Basic and Applied Sciences, 2010. 4 (12): p. 58135822 .

[15] de Luque, M. S., et al., Unrequited profit: How stakeholder and economic values relate to subordinates' perceptions of leadership and firm performance. Administrative Science Quarterly, 2008. 53 (4): p. 626-654.

[16] Hosmer, D. W., et al., A comparison of goodness-of-fit tests for the logistic regression model. Statistics in medicine, 1997. 16 (9): p. 965-980.

[17] Park, H., An introduction to logistic regression: from basic concepts to interpretation with particular attention to nursing domain. Journal of Korean Academy of Nursing, 2013. 43 (2): p. $154-164$.

[18] Amsalu, A. "The challenges in control COVID-19 in Injibera, Awi Zone, North East Amhara, Ethiopia." (2021). 